\title{
Cardiac incoordination induced by left bundle branch block: its relation with left ventricular systolic function in patients with and without cardiomyopathy
}

\author{
Miguel Quintana*1, Samir Saha², Satish Govind², Lars Åke Brodin², \\ Francesca del Furia ${ }^{2}$ and Vicente Bertomeu ${ }^{3}$
}

\author{
Address: ${ }^{1}$ Institution of Laboratory Medicine, Department of Cardiology, Hospital de Torrevieja, Spain, ${ }^{2}$ Karolinska University Hospital, \\ Huddinge, Stockholm, Sweden and ${ }^{3}$ Departamento de Cardiología, Hospital Universitario de San Juan, Alicante, Spain \\ Email: Miguel Quintana* - miguel.quintana@ki.se; Samir Saha - samir.saha@ki.se; Satish Govind - Satishgovind@mail.com; \\ Lars Åke Brodin - lars-ake.brodin@syd.kth.se; Francesca del Furia - f.delfuria@libero.it; Vicente Bertomeu - bertomeuv@gva.es \\ * Corresponding author
}

Published: 5 August 2008

Cardiovascular Ultrasound 2008, 6:39 doi:10.1 186/1476-7/20-6-39
Received: 2 June 2008

Accepted: 5 August 2008

This article is available from: http://www.cardiovascularultrasound.com/content/6/1/39

(C) 2008 Quintana et al; licensee BioMed Central Ltd.

This is an Open Access article distributed under the terms of the Creative Commons Attribution License (http://creativecommons.org/licenses/by/2.0), which permits unrestricted use, distribution, and reproduction in any medium, provided the original work is properly cited.

\begin{abstract}
Background: Although left bundle branch block (LBBB) alters the electrical activation of the heart, it is unknown how it might change the process of myocardial coordination (MC) and how it may affect the left ventricular (LV) systolic function. The present study assessed the effects of LBBB on MC in patients with LBBB with and without dilated (DCMP) or ischemic cardiomyopathy (ICMP).
\end{abstract}

Methods: Tissue Doppler echocardiography (TDE) was performed in 86 individuals: 21 with isolated LBBB, 26 patients with DCMP + LBBB, 19 patients with ICMP + LBBB and in 20 healthy individuals (Controls). $M C$ was assessed analyzing the myocardial velocity profiles obtained from six basal segments of the LV using TDE. The LV systolic function was assessed by standard twodimensional echocardiography and by TDE.

Results: Severe alterations in MC were observed in subjects with LBBB as compared with controls $(P<0.0$ I for all comparisons); these derangements were even worse in patients with $D C M P$ and ICMP $(P<0.00$ I for comparisons with Controls and $P<0.0$ I for comparison with individuals with isolated LBBB). Some parameters of MC differed significantly between DCMP and ICMP $(P<0.0 \mathrm{I})$. $A$ good or very good correlation coefficient was found between variables of $M C$ and variables of LV systolic function.

Conclusion: LBBB induces severe derangement in the process of $M C$ that are more pronounced in patients with cardiomyopathies and that significantly correlates with the LV systolic function. The assessment of MC may help in the evaluation of the etiology of dilated cardiomyopathy.

\section{Introduction}

Left bundle branch block (LBBB) alters the pattern of electrical activation of the heart [1-4] and disturbs the left ven- tricular (LV) systolic function[1,5-7] even in absence of other cardiovascular diseases[8]. The presence of LBBB in patients with dilated (DCMP) or ischemic cardiomyopa- 
thy (ICMP) implies a progressive worsening of the $\mathrm{LV}$ systolic function and prognosis [9-13]. In these patients cardiac resynchronization therapy (CRT) improves shortand long-term hemodynamics, functional capacity, quality of life and survival [14-18]. However, even following simple electrocardiographic and echocardiographic selection criteria for CRT $[19,20]$ one third to one fourth of the patients do not respond to or even worsens after CRT[17,21-23]. Consequently, different techniques, including Tissue Doppler echocardiography (TDE) have been used to detect inter and intra-ventricular cardiac dyssynchrony, to evaluate its effects on LV systolic function, and to assess the effects of CRT [24-28]. Although a delayed mechanical contraction of some LV walls plays an important role in the LV hemodynamics, it is less known how a delayed electrical activation might affect the process of myocardial coordination (MC), defined as the synchronicity of time-related events occurring before mechanical contraction and ventricular filling, and how an alteration in MC might affect the LV contraction and hemodynamics. The present study was thus designed to assess the physiological basis of MC in patients with LBBB with or without DCMP or ICMP by means of TDE.

\section{Patients and methods \\ Patients and controls}

The studied population consisted of 86 individuals: 21 with isolated LBBB but otherwise healthy, 26 patients with DCMP and LBBB, 19 patients with ICMP and LBBB, and 20 healthy individuals (Controls). The controls, being part of a study in the geriatric population[29], were asymptomatic without treatment with cardiovascular pharmacological agents and had a normal rest ECG, a normal standard echocardiogram, and a normal exercise test. Individuals with LBBB were also asymptomatic and were recruited from an ECG-database; none of them were on treatment with cardiovascular pharmacological agents and all of them had been referred to a rest ECG as a routine procedure before a non-cardiovascular surgical intervention. Among patients with DCMP and ICMP, 84\% were on treatment with diuretics, $78 \%$ were on betablocker agents, $72 \%$ were on angiotensine converting enzyme inhibitors or angiotensine II receptor blockers, $67 \%$ were on aspirin, $42 \%$ on digoxin, and $34 \%$ on oral anticoagulants. All participants gave a written consent and the ethical committee at the Karolinska University Hospital, Huddinge, approved the study.

\section{Standard echocardiography}

Echocardiography was performed with a System $\mathrm{V}^{\mathrm{TM}}$ equipment (General Electric, Vingmed, Horten, Norway) using a $2.5-\mathrm{MHz}$ probe for image acquisition. The images were acquired in parasternal long and short axis as well as in apical four- and two-chamber projections. Left atrial and LV dimensions and function were assessed by stand- ard methods and LV volumes and ejection fraction were calculated by the Simpson's method, averaging values from three consecutive cardiac cycles[30].

\section{Tissue Doppler Echocardiography (TDE)}

Images were obtained from the apical four and two-chamber views as well as from the apical long-axis view. The pulse repetition frequency and the ultrasound sector beam image width and depth were modulated to avoid the Nyqvist's upper frequency while obtaining images with at least 100 frames per second. Five consecutive cardiac cycles were acquired during post-expiratory apnea in each of the above-mentioned projections and the images were analyzed off-line using an EchoPAC ${ }^{\mathrm{TM}}$ 6.3.6 software (General Electric, Horten, Norway).

A $2 \mathrm{~mm}$ sample volume was placed at the basal segment of the LV near the A-V plane in the following walls: the posterior septum and lateral walls (in the 4-chamber view), inferior and anterior walls (in the two-chamber view), and posterior wall and anterior septum (in the long-axis apical view). As previously described[29] and as shown in figure $1 \mathrm{a}, \mathrm{MC}$ was studied from the myocardial velocity profile curves, calculating the following temporal events during the cardiac cycle: The electro-mechanical delay time, the electro-hemodynamic delay time, the isovolumic contraction time, the ejection time and the isovolumic relaxation time. The electro-mechanical delay time was defined as the time interval between the start of the QRS complex and the beginning of the mechanical activity on the myocardial velocity curve. The electro-hemodynamic delay time was defined as the time interval between the start of the QRS complex and the beginning of the ejection time. The isovolumic contraction time was calculated by subtracting the electro-mechanical delay time from the electro-hemodynamic delay time. The ejection time was defined as the time interval between the opening and closure of the aortic valve characterized by the descent of the myocardial velocity profile curve to the baseline. The isovolumic relaxation time was defined as the time interval between the closure of the aortic valve and the opening of the mitral valve characterized by the beginning of the $\mathrm{E}^{\prime}$ wave; when a post-systolic velocity was present, the beginning of the isovolumic relaxation time was measured at the peak of that velocity. Using TDE, the LV systolic function was calculated by means of the peak systolic velocity (PSV) of all LV walls and by the temporal integration of the PSV curve, a measure of the $\mathrm{A}-\mathrm{V}$ plane displacement that assess the longitudinal LV systolic function. All the above-mentioned measures are expressed as the average of the values obtained at each of the basal segments of the six LV walls.

\section{Statistical analysis}

The values are expressed as means \pm standard deviation. ANOVA was used to test differences among groups, fol- 

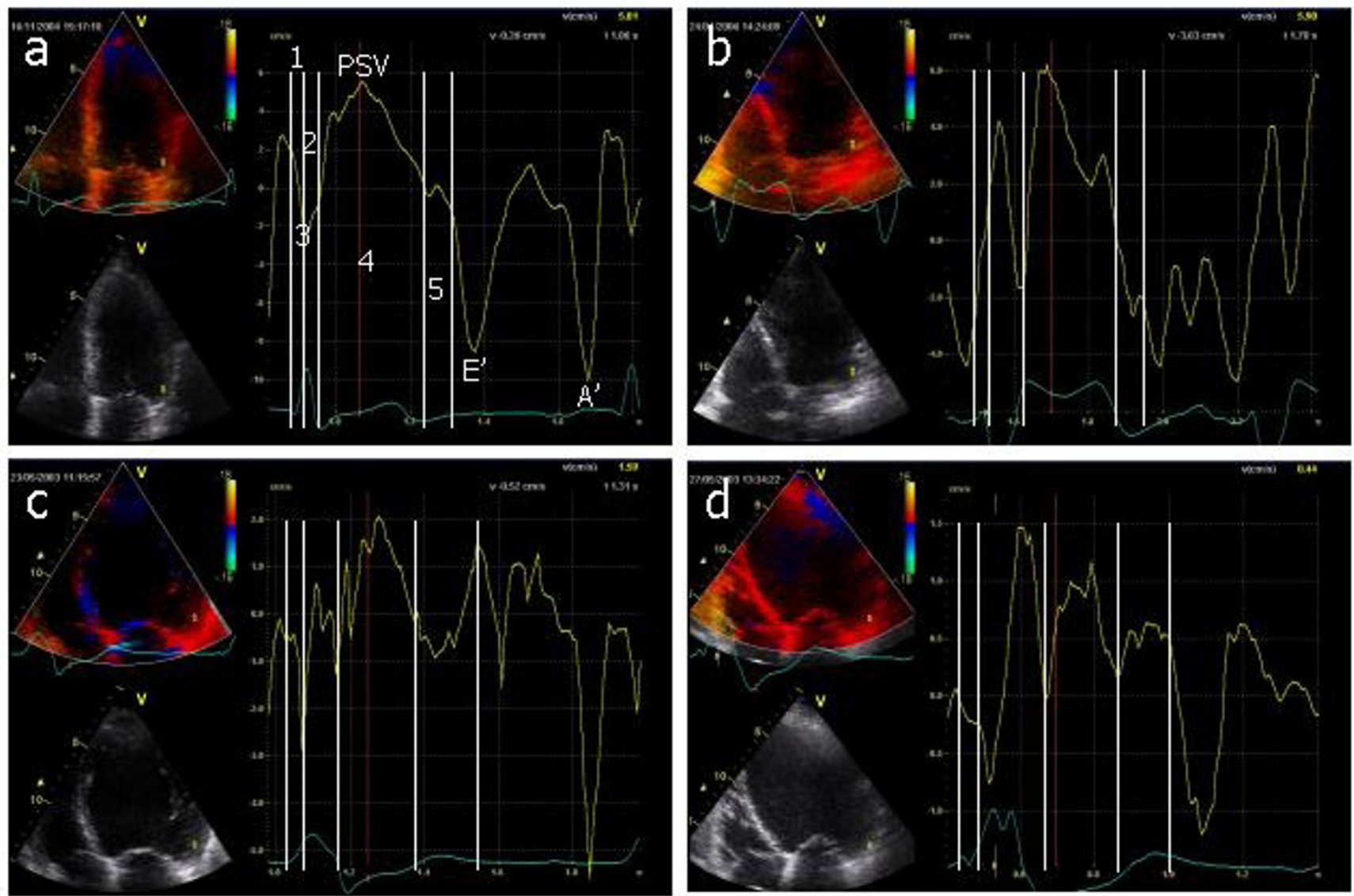

Figure I

a. Echocardiographic image showing the apical four-chamber view in a subject of the control group. The image shows the myocardial velocity profile obtained in the basal segment of the left ventricular lateral wall. The time intervals identified by figures indicate: I = Electromechanical delay time (EMDT); 2 = Isovolumic contraction time (IVCT); $3=$ Electro hemodynamic delay time (EHDT); 4 = Ejection time (ET); 5 = Isovolumic relaxation time (IVRT). $A^{\prime}=$ Late diastolic $(A-w a v e)$ velocity); $E^{\prime}=$ Early (E-wave) diastolic velocity; $P S V=$ Peak systolic velocity. $b$, represent the same image in a patient with isolated LBBB; $c$ in a patient with dilated cardiomyopathy and LBBB; $d$ in a patient with ischemic cardiomyopathy and LBBB.

lowed by the Tukey test for post-hoc comparisons between groups. The correlation coefficient was used to establish relationships between variables expressing the LVSF and variables expressing MC. A $P$ value $<0.05$ was considered statistically significant.

\section{Results}

As shown in table 1, the Controls were older than the other groups $(\mathrm{P}<0.001$ for all comparisons $)$. Age was however similar among patients with isolated LBBB and patients with DCMP and with ICMP. Males and females were similarly represented in all groups, except in patients with DCMP and with ICMP in which males were over represented. Differences observed in left atrial diameter, septum and posterior wall thicknesses, LV end-diastolic diameter and volumes, and LVEF are shown in table 1. No differences were found between DCMP and ICMP groups regarding those variables; however, significantly differences were found between DCMP and ICMP groups compared with Controls and compared with the LBBB group.

Table 2 shows all measures of MC assessed by TDE in the entire population. The electro-mechanical delay time was shorter in the Controls group than in the other groups ( $\mathrm{P}$ $<0.001$ for all comparisons); however, this interval was similar among LBBB, DCMP and ICMP groups. The electro-hemodynamic delay time was shorter in the Controls group than in the other groups $(\mathrm{P}<0.001$ for all comparison); it was also shorter in the DCMP and ICMP groups as compared with the LBBB group $(\mathrm{P}<0.01$ for both comparisons), and shorter in the ICMP group than in the DCMP group $(\mathrm{P}<0.01)$. Findings similar to these were observed with respect to the isovolumic relaxation time. The isovolumic contraction time was shorter in the Controls 
Table I: Demographics and standard echocardiographic variables.

\begin{tabular}{|c|c|c|c|c|c|}
\hline Variables & Controls $\mathbf{N}=\mathbf{2 0}$ & LBBB $\mathbf{N}=21$ & ICMP N = I9 & DCMP N $=26$ & $\mathbf{P}$ \\
\hline Age, years & $70 \pm 4$ & $61 \pm 8^{*}$ & $61 \pm 9 *$ & $65 \pm 9 *$ & $<0.001$ \\
\hline Gender, (M/F) & $10 / 10$ & $11 / 10$ & $17 / 2$ & $21 / 5$ & 0.01 \\
\hline QRS, ms & $84 \pm 4$ & $145 \pm 9 *$ & $150 \pm 9 *$ & $154 \pm 9 *$ & $<0.001$ \\
\hline LA diameter, $\mathrm{mm}$ & $34 \pm 5$ & $37 \pm 8$ & $49 \pm 10^{*} t$ & $48 \pm 10 * t$ & $<0.001$ \\
\hline SWT, mm & $\mathrm{II} \pm 0.7$ & $11 \pm 1.3$ & $9.7 \pm 1.9 \dagger$ & $9.2 \pm 1.9 * \dagger$ & $<0.01$ \\
\hline PWT, mm & $\mathrm{II} \pm 1.0$ & $10 \pm 1.0$ & $10 \pm 2.1$ & $10 \pm 1.8$ & NS \\
\hline LVEDD, mm & $43 \pm 6$ & $46 \pm 6$ & $75 \pm 8^{*} \dagger$ & $72 \pm 12^{*}+$ & $<0.001$ \\
\hline LVEDV, ml & $99 \pm 23$ & $114 \pm 36$ & $247 \pm 73^{*}+$ & $274 \pm 123^{*}+$ & $<0.001$ \\
\hline LVESV, ml & $46 \pm 10$ & $63 \pm 26$ & $177 \pm 62^{*}+$ & $203 \pm 105^{*} \dagger$ & $<0.001$ \\
\hline LVEF, \% & $54 \pm 4$ & $46 \pm 8^{*}$ & $27 \pm 10 * t$ & $29 \pm 7 * \dagger$ & $<0.001$ \\
\hline
\end{tabular}

Abbreviations: $L A=$ Left atrium; LVEDD = Left ventricular end diastolic diameter; $L V E F=$ Left ventricular ejection fraction; LVEDV $=$ Left ventricular end diastolic volume; LVESV = Left ventricular end systolic volume; PWT = Posterior wall thickness; SWT = Septal wall thickness. $P=$ Analysis of variance.

$*<0.05$ vs. Controls.

$\dagger<0.05$ vs. LBBB.

group than in the other groups $(\mathrm{P}<0.001$ for all comparisons); it was shorter in the ICMP and the DCMP groups as compared with the LBBB group $(\mathrm{P}<0.01$ for both comparisons), but was similar in the DCMP and the ICMP groups. Findings similar to these were observed with respect to the ejection time. The PSV was higher in the Controls group as compared with the other groups $(\mathrm{P}<0.001$ for all comparisons); it was lower in the DCMP and ICMP groups as compared with the LBBB group $(\mathrm{P}<0.01$ for both comparisons), but it was similar in the DCMP and ICMP groups. Findings similar to these were observed for the $\mathrm{A}-\mathrm{V}$ plane displacement variable.

Table 3 shows the correlation coefficients between several variables of LV systolic function and MC. Of interest is to note the very good correlation coefficient between the isovolumic relaxation time and the PSV (see figure 2), between the electro-hemodynamic delay time and the PSV, and between the ejection time and the A-V plane displacement. The correlation coefficient between the other studied variables was in between fair and good.

\section{Discussion}

The present study showed that: 1) LBBB considerably alters $\mathrm{MC}$ as evidenced by a prolongation of the electromechanical delay time, the electro-hemodynamic delay time, the isovolumic contraction time and the isovolumic relaxation time, and by a shortening of the ejection time; 2) In patients with DCMP and ICMP these derangements were more pronounced; 3) Some variables, viz. the electro-hemodynamic delay time and the isovolumic relaxation time made it possible to differentiate patients from the DCMP and the ICMP groups; 4) A good or very good coefficient of correlation was found between variables of $\mathrm{MC}$ and of LV systolic function demonstrating that the larger the derangement in $\mathrm{MC}$, the poorer the $\mathrm{LV}$ systolic function. The present findings may explain the mechanisms of poorer LV systolic function and the poorer prognosis in patients with cardiomyopathies with LBBB than in those without LBBB [9-13].

As known, the myocardial coupling and uncoupling processes (electro-hemodynamic delay time and the isovolu-

Table 2: Parameters of myocardial coordination and left ventricular systolic function obtained by tissue Doppler echocardiography.

\begin{tabular}{|c|c|c|c|c|c|}
\hline Variables & Controls $\mathbf{N}=\mathbf{2 0}$ & LBBB $\mathbf{N}=21$ & ICMP N = 19 & DCMP N $=26$ & $\mathbf{P}$ \\
\hline EMDT, ms & $14 \pm 1$ & $45 \pm 4^{*}$ & $42 \pm 9 *$ & $47 \pm 12^{*}$ & $<0.001$ \\
\hline EHDT, ms & $81 \pm 10$ & $136 \pm 10 *$ & $136 \pm 25^{*}$ & $163 \pm 33^{*}+\ddagger$ & $<0.001$ \\
\hline IVCT, ms & $67 \pm 9$ & $91 \pm 8^{*}$ & $96 \pm 18^{*}$ & $116 \pm 31 * t$ & $<0.001$ \\
\hline IVRT, ms & $70 \pm 10$ & $134 \pm 18^{*}$ & $127 \pm 34^{*}+$ & $160 \pm 29 * \dagger \ddagger$ & $<0.001$ \\
\hline $\mathrm{ET}, \mathrm{ms}$ & $321 \pm 20$ & $278 \pm 4 I^{*}$ & $207 \pm 28^{*}+$ & $220 \pm 44 *+$ & $<0.001$ \\
\hline $\mathrm{PSV}, \mathrm{cm} / \mathrm{s}$ & $6.3 \pm 1.1$ & $4.1 \pm 0.8^{*}$ & $2.6 \pm 0.8^{*}+$ & $3.2 \pm 1.0 * \dagger$ & $<0.001$ \\
\hline $\mathrm{A}-\mathrm{V}, \mathrm{mm}$ & $9.7 \pm 1.5$ & $8.0 \pm 1.8^{*}$ & $3.9 \pm 1.6 * t$ & $5.6 \pm 2.8^{*}+$ & $<0.001$ \\
\hline
\end{tabular}

Abbreviations: $\mathrm{A}-\mathrm{V}=$ Atrio-ventricular plane displacement; $\mathrm{EHDT}=$ Electro-hemodynamic delay time; $\mathrm{EMDT}=$ Electro-mechanical delay time; $\mathrm{ET}$ $=$ Ejection time; IVCT = Isovolumic contraction time; IVRT = Isovolumic relaxation time; PSV = Peak systolic velocity.

$\mathrm{P}=$ Analysis of variance.

$*<0.05$ vs. Controls.

$t<0.05$ vs. LBBB.

$\ddagger<0.05$ vs. ICMP. 


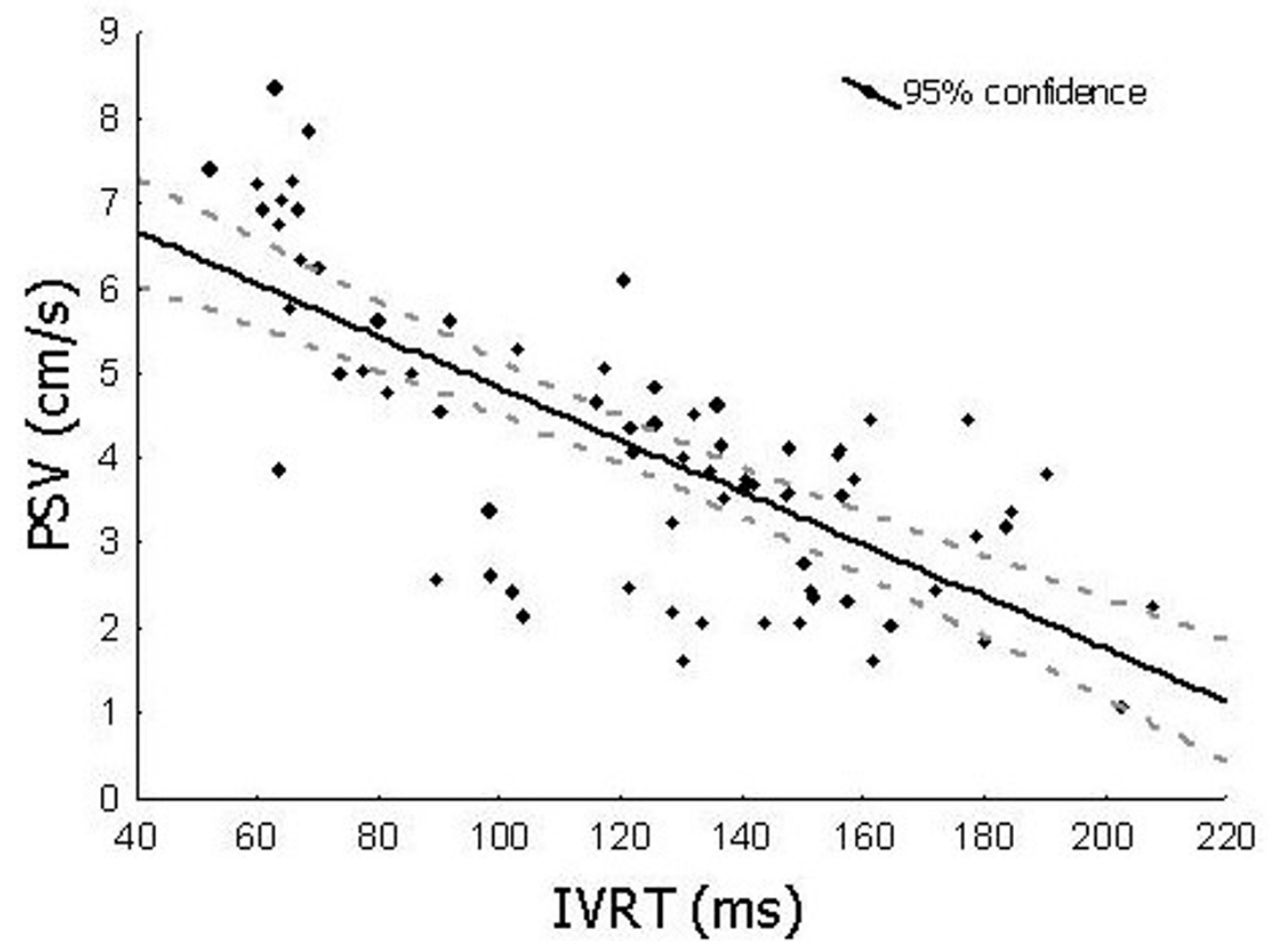

Figure 2

Scatter plot of the correlation coefficient $(r=-0.74)$ between a variable expressing the left ventricular systolic function, (PSV = peak systolic velocity) and a variable expressing the left ventricular myocardial coordination (IVRT = the isovolumic relaxation time).

mic relaxation time) are energy demanding[31], indicating that their excessive prolongation imply a higher energy expenditure with a less effective LV hemodynamic work. In the present study, an exaggerated prolongation of the electro-mechanical and electrohemodynamic delay times resulted in a remarkable shortening of the ejection time that shortened the effective LV hemodynamic working time. On the other hand (although not shown in the present study) a striking prolongation of the isovolumic relaxation time could signifi-

Table 3: Correlation coefficients corresponding to variables expressing myocardial coordination and variables expressing left ventricular systolic function.

\begin{tabular}{llllll}
\hline & EMDT & EHDT & IVCT & IVRT & ET \\
\hline LVEF & -0.53 & -0.63 & -0.59 & -0.63 & 0.64 \\
PSV & -0.61 & -0.71 & -0.63 & -0.74 & 0.68 \\
A-V & -0.45 & -0.53 & -0.49 & -0.59 & 0.74 \\
\hline
\end{tabular}

Abbreviations: A-V = Atrio-ventricular plane displacement; EHDT = Electro hemodynamic delay time; EMDT = Electro mechanical delay time; ET = Ejection time; IVCT = Isovolumic contraction time; IVRT = Isovolumic relaxation time; LVEF = Left ventricular ejection fraction; PSV = Peak systolic velocity. cantly shorten the LV early filling time, a fact that in presence of $\mathrm{A}-\mathrm{V}$ conduction disturbances (a common finding in patients with cardiomyopathies) could lead to a rise in the LV end-diastolic pressure, to an impairment of the LV filling during atrial systole, and to a generation of diastolic mitral regurgitation that finally, could contribute to an additional diminution of the LV stroke volume.

The good correlation coefficient between the variables of $\mathrm{MC}$ and LV systolic function does not necessarily establish a cause-effect relationship between them, though it is probable that the poor or the lack of $\mathrm{MC}$ found in patients with LBBB and cardiomyopathies could be an additional cause of deterioration of LV systolic function seen in these patients. The intrinsic poor contractile function together with the hemodynamic imbalance induced by the interand intra-ventricular dyssynchrony usually observed in these patients are additional known factors for poor LV systolic function. To what extent the lack of MC or the inter- and intra-ventricular dyssynchrony contribute to the deterioration of the LV systolic function and to what extent these processes coexist is difficult to ascertain. Surely all these mechanisms (poor contractility, lack of 
$\mathrm{MC}$ and inter- and intra-ventricular dyssynchrony) alone or together play an important role in the deterioration of LV systolic function.

Though some parameters of MC were more altered in patients with DCMP than in patients with ICMP, the current results cannot yet be used to make the differential diagnosis of these entities. The findings may, however, lead to future investigations for testing new hypothesis; for example, although the coupling and uncoupling processes were more prolonged in patients with DCMP than in those with ICMP, the LV systolic function was poorer in the last group as compared with the former (lower values of PSV and A-V plane displacement). This apparent contradiction may be explained by the fact that patients with DCMP may have a myocardial contractile reserve that is larger than in patients with ICMP. It could then be hypothesized that patients with moderately depressed myocardial contractile reserve but severely depressed $\mathrm{MC}$ (patients with DCMP) may better respond to CRT than those with severely depressed myocardial contractile reserve but with only moderately depressed MC (patients with ICMP). Indeed, the subgroup analysis of some cohort studies[25,32] and of a randomized trial[18] of patients treated with CRT points into that direction. In addition one of the independent predictive factors of clinical outcome in patients with CRT was a preserved myocardial contractile reserve assessed during dobutamine stress echocardiography[33].

Although TDE has not been used to select patients for CRT in large randomized clinical trials, this technique together with other methods have been used to estimate the results of such therapy[26,34-37]. However, most of the publications refer to the evaluation of the changes in the LV systolic function after CRT and practically none of the mentioned studies addressed the evaluation of the effects of CRT on MC. In addition, the number of non-responders to CRT in some of the above mentioned studies is much larger when the response is evaluated in terms of improvement of echocardiographic variables of reverse remodeling $[22,24,26]$ than when the response is evaluated using subjective or relatively objective parameters of functional capacity $[23,38-41]$, which may in some way question the validity or the usefulness of the echocardiographic variables studied a fact that has recently been tested in the PROSPECT trial[42]. One possible explanation for these results rests on the fact that the time to peak systolic velocity or the time to peak systolic strain or strain rate used in most of the mentioned studies[24,26,43,44] are parameters extremely difficult to reliably assess in patients with severely reduced LV systolic function; as seen figure $1 \mathrm{c}$ and $1 \mathrm{~d}$, the time to PSV is difficult to determine accurately. Assessing the other different time intervals by TDE technique as done in the present study may represent an alternative way to assess both $\mathrm{MC}$ and cardiac dyssynchrony that may help to a better selection of candidates for CRT as shown in the PROSPECT trial in which the left ventricular preejection interval and time to onset of systolic velocity (parameters expressing MC) were the only echocardiographic parameter that predicted response to CRT[42].

\section{Study limitations}

As the main aim of the present study was to evaluate the effects of LBBB on MC and of it's repercussion on LV systolic function, the study did not include patients with cardiomyopathies without LBBB; therefore we could not assess the degree of MC and it's effect on LVSF in that group of patients, as shown in previous studies $[45,46]$. Although the temporal events during the cardiac cycle have been studied with some reliability and confidence by means of TDE in normal individuals [8], the reproducibility of those temporal events needs to be confirmed in patients with DCMP or with ICMP by other investigators. Although all parameters of $\mathrm{MC}$ were obtained by averaging the values obtained in the six basal LV segments, it has to be acknowledged that those values, due to the reasons intrinsically related to the acquisition technique, were not simultaneously obtained during the same cardiac cycle.

\section{Conclusion}

LBBB introduces severe derangements in the process of $\mathrm{MC}$ that are more pronounced in patients with cardiomyopathies. There are good correlations between the variables expressing MC and LV systolic function, indicating that these processes are closely related irrespective of background pathologies associated with $\mathrm{LBBB}$, and that one important determinant of deterioration of LV systolic function could be the degree of loss of MC. The electrophysiological, electromechanical, and hydraulic events that represent $\mathrm{MC}$ may help to differentiate patients with DCMP from those with ICMP and that may be used as additional criteria for patient selection for CRT.

\section{List of abbreviations}

A-V: Atrio-Ventricular; DCMP: Dilated cardiomyopathy of unknown origin; EHDT: Electro-hemodynamic delay time; EMDT: Electro-mechanical delay time; ET: Ejection time; ICMP: Ischemic cardiomyopathy of ischemic origin; IVCT: Isovolumic contraction time; IVRT: Isovolumic relaxation time; LBBB: Left bundle branch block; LV: Left ventricle (ventricular); MC: Myocardial coordination; PSV: Peak systolic velocity; TDE: Tissue Doppler Echocardiography.

\section{Authors' contributions}

MQ: Made substantial contributions to conception and design, or acquisition of data, or analysis and interpretation of data; mainly responisble for drafting the manu- 
script and gave final approval of the version to be published. SS: Contributed with data acquisition and interpretation, participated in drafting process and approved the final version. SG: Contributed with data acquisition and interpretation, statistical analysis, participated in drafting process and approved the final version. LÅB: Made substantial contributions to conception and design, participated in drafting process and approved the final version. FdF: Contributed with data acquisition and interpretation, statistical analysis, participated in drafting process and approved the final version. VB: Made substantial contributions to conception and design, participated in drafting process and approved the final version.

\section{References}

I. Grines CL, Bashore TM, Boudoulas H, Olson S, Shafer P, Wooley CF: Functional abnormalities in isolated left bundle branch block. The effect of interventricular asynchrony. Circulation 1989, 79:845-853.

2. Auricchio A, Fantoni C, Regoli F, Carbucicchio C, Goette A, Geller $\mathrm{C}$, Kloss $\mathrm{M}$, Klein $\mathrm{H}$ : Characterization of left ventricular activation in patients with heart failure and left bundle-branch block. Circulation 2004, 109: I I33-1 I39.

3. Rodriguez LM, Timmermans C, Nabar A, Beatty G, Wellens HJ: Variable patterns of septal activation in patients with left bundle branch block and heart failure. J Cardiovasc Electrophysiol 2003, 14:|35-|4|.

4. Vassallo JA, Cassidy DM, Marchlinski FE, Buxton AE, Waxman HL, Doherty JU, Josephson ME: Endocardial activation of left bundle branch block. Circulation 1984, 69:914-923.

5. Tantengco MV, Thomas RL, Karpawich PP: Left ventricular dysfunction after long-term right ventricular apical pacing in the young. J Am Coll Cardiol 200I, 37:2093-2100.

6. van Oosterhout MF, Prinzen FW, Arts T, Schreuder J], Vanagt WY, Cleutjens JP, Reneman RS: Asynchronous electrical activation induces asymmetrical hypertrophy of the left ventricular wall. Circulation 1998, 98:588-595.

7. Prinzen FW, Peschar M: Relation between the pacing induced sequence of activation and left ventricular pump function in animals. Pacing Clin Electrophysiol 2002, 25:484-498.

8. Quintana M, Saha S, Rohani M, del Furia F, Roumina MS, Lind B, Hayashi S, Brodin LA: Electromechanical coupling, uncoupling, and ventricular function in patients with bundle branch block: a tissue-Doppler echocardiographic study. Echocardiography 2004, $21: 687-698$

9. Baldasseroni S, Opasich C, Gorini M, Lucci D, Marchionni N, Marini M, Campana C, Perini G, Deorsola A, Masotti G, Tavazzi L, Maggioni AP: Left bundle-branch block is associated with increased Iyear sudden and total mortality rate in 5517 outpatients with congestive heart failure: a report from the Italian network on congestive heart failure. Am Heart J 2002, I 43:398-405.

10. Shamim W, Francis DP, Yousufuddin M, Varney S, Pieopli MF, Anker SD, Coats AJ: Intraventricular conduction delay: a prognostic marker in chronic heart failure. Int / Cardiol 1999, 70: 171-178.

11. Xiao HB, Roy C, Fujimoto S, Gibson DG: Natural history of abnormal conduction and its relation to prognosis in patients with dilated cardiomyopathy. Int J Cardiol 1996, 53:163-170.

12. Shamim W, Yousufuddin M, Cicoria M, Gibson DG, Coats AJ, Henein MY: Incremental changes in QRS duration in serial ECGs over time identify high risk elderly patients with heart failure. Heart 2002, 88:47-5I.

13. Bode-Schnurbus L, Bocker D, Block M, Gradaus R, Heinecke A, Breithardt G, Borggrefe M: QRS duration: a simple marker for predicting cardiac mortality in ICD patients with heart failure. Heart 2003, 89:1157-1162.

14. Young JB, Abraham WT, Smith AL, Leon AR, Lieberman R, Wilkoff B, Canby RC, Schroeder JS, Liem LB, Hall S, Wheelan K: Combined cardiac resynchronization and implantable cardioversion defibrillation in advanced chronic heart failure: the MIRACLE ICD Trial. Jama 2003, 289:2685-2694.
15. Cazeau S, Leclercq C, Lavergne T, Walker S, Varma C, Linde C, Garrigue S, Kappenberger L, Haywood GA, Santini M, Bailleul C, Daubert JC: Effects of multisite biventricular pacing in patients with heart failure and intraventricular conduction delay. $\mathrm{N} \mathrm{Engl} \mathrm{J}$ Med 200I, 344:873-880.

16. Auricchio A, Stellbrink C, Sack S, Block M, Vogt J, Bakker P, Huth C, Schondube F, Wolfhard U, Bocker D, Krahnefeld O, Kirkels H: Longterm clinical effect of hemodynamically optimized cardiac resynchronization therapy in patients with heart failure and ventricular conduction delay. J Am Coll Cardiol 2002, 39:2026-2033.

17. Abraham WT, Fisher WG, Smith AL, Delurgio DB, Leon AR, Loh E, Kocovic DZ, Packer M, Clavell AL, Hayes DL, Ellestad M, Trupp RJ, Underwood J, Pickering F, Truex C, McAtee P, Messenger J: Cardiac resynchronization in chronic heart failure. N Engl J Med 2002, 346:1845-1853

18. Cleland JG, Daubert JC, Erdmann E, Freemantle N, Gras D, Kappenberger $L$, Tavazzi $L$ : The effect of cardiac resynchronization on morbidity and mortality in heart failure. N Engl J Med 2005, 352:1539-1549.

19. Gregoratos G, Abrams J, Epstein AE, Freedman RA, Hayes DL, Hlatky MA, Kerber RE, Naccarelli GV, Schoenfeld MH, Silka MJ, Winters SL, Gibbons RJ, Antman EM, Alpert JS, Hiratzka LF, Faxon DP, Jacobs AK, Fuster V, Smith SC Jr.: ACC/AHA/NASPE 2002 guideline update for implantation of cardiac pacemakers and antiarrhythmia devices: summary article: a report of the American College of Cardiology/American Heart Association Task Force on Practice Guidelines (ACC/AHA/NASPE Committee to Update the 1998 Pacemaker Guidelines). Circulation 2002, 106:2145-2161.

20. Auricchio A, Stellbrink C, Butter C, Sack S, Vogt J, Misier AR, Bocker D, Block M, Kirkels JH, Kramer A, Huvelle E: Clinical efficacy of cardiac resynchronization therapy using left ventricular pacing in heart failure patients stratified by severity of ventricular conduction delay. J Am Coll Cardiol 2003, 42:2109-2II6.

21. Pitzalis MV, lacoviello M, Romito R, Massari F, Rizzon B, Luzzi G, Guida P, Andriani A, Mastropasqua F, Rizzon P: Cardiac resynchronization therapy tailored by echocardiographic evaluation of ventricular asynchrony. Journal of the American College of Cardiology $1615,40: 1615-1622$.

22. Yu CM, Fung WH, Lin H, Zhang Q, Sanderson JE, Lau CP: Predictors of left ventricular reverse remodeling after cardiac resynchronization therapy for heart failure secondary to idiopathic dilated or ischemic cardiomyopathy. American Journal of Cardiology 2003, 91:684-688

23. Reuter S, Garrigue S, Barold SS, Jais P, Hocini M, Haissaguerre M, Clementy J: Comparison of characteristics in responders versus nonresponders with biventricular pacing for drug-resistant congestive heart failure. Am J Cardiol 2002, 89:346-350.

24. Yu CM, Fung JW, Zhang Q, Chan CK, Chan YS, Lin H, Kum LC, Kong SL, Zhang Y, Sanderson JE: Tissue Doppler imaging is superior to strain rate imaging and postsystolic shortening on the prediction of reverse remodeling in both ischemic and nonischemic heart failure after cardiac resynchronization therapy.[see comment]. Circulation 2004, I 1 0:66-73.

25. St John Sutton MG, Plappert T, Abraham WT, Smith AL, DeLurgio DB, Leon AR, Loh E, Kocovic DZ, Fisher WG, Ellestad M, Messenger J, Kruger K, Hilpisch KE, Hill MR: Effect of cardiac resynchronization therapy on left ventricular size and function in chronic heart failure. Circulation 2003, 107:1985-1990.

26. Sogaard P, Egeblad H, Kim WY, Jensen HK, Pedersen AK, Kristensen BO, Mortensen PT: Tissue Doppler imaging predicts improved systolic performance and reversed left ventricular remodeling during long-term cardiac resynchronization therapy. Journal of the American College of Cardiology 2002, 40:723-730.

27. Ansalone G, Giannantoni P, Ricci R, Trambaiolo P, Laurenti A, Fedele $F$, Santini M: Doppler myocardial imaging in patients with heart failure receiving biventricular pacing treatment. American Heart Journal 200I, I 42:88I-896.

28. Gorcsan J 3rd, Kanzaki H, Bazaz R, Dohi K, Schwartzman D: Usefulness of echocardiographic tissue synchronization imaging to predict acute response to cardiac resynchronization therapy. Am J Cardiol 2004, 93: I I78-I I8I.

29. Quintana M, Saha SK, Rohani M, Del Furia F, Bjernby J, Lind B, Brodin LA: Assessment of the longitudinal and circumferential left ventricular function at rest and during exercise in healthy 
elderly individuals by tissue-Doppler echocardiography: relationship with heart rate. Clin Sci (Lond) 2004, 106:45 I-457.

30. Schiller NB, Shah PM, Crawford M, DeMaria A, Devereux R, Feigenbaum H, Gutgesell H, Reichek N, Sahn D, Schnittger I, et al.: Recommendations for quantitation of the left ventricle by twodimensional echocardiography. American Society of Echocardiography Committee on Standards, Subcommittee on Quantitation of Two-Dimensional Echocardiograms. J Am Soc Echocardiogr 1989, 2:358-367.

31. Ukkonen H, Beanlands RS, Burwash IG, de Kemp RA, Nahmias C, Fallen E, Hill MR, Tang AS: Effect of cardiac resynchronization on myocardial efficiency and regional oxidative metabolism. Circulation 2003, 107:28-31.

32. Gasparini M, Mantica M, Galimberti P, Genovese L, Pini D, Faletra F, Marchesina UL, Mangiavacchi M, Klersy C, Gronda E: Is the outcome of cardiac resynchronization therapy related to the underlying etiology? Pacing Clin Electrophysiol 2003, 26: I75-I80

33. Da Costa A, Thevenin J, Roche F, Faure E, Romeyer-Bouchard C, Messier M, Convert G, Barthelemy JC, Isaaz K: Prospective validation of stress echocardiography as an identifier of cardiac resynchronization therapy responders. Heart Rhythm 2006, 3:406-4I3

34. Breithardt OA, Stellbrink C, Kramer AP, Sinha AM, Franke A, Salo R, Schiffgens B, Huvelle E, Auricchio A, Path-Chf Study Group. Pacing Therapies for Congestive Heart Failure: Echocardiographic quantification of left ventricular asynchrony predicts an acute hemodynamic benefit of cardiac resynchronization therapy. Journal of the American College of Cardiology 2002, 40:536-545.

35. Bax JJ, Marwick TH, Molhoek SG, Bleeker GB, van Erven L, Boersma $E$, Steendijk $P$, van der Wall EE, Schalij MJ: Left ventricular dyssynchrony predicts benefit of cardiac resynchronization therapy in patients with end-stage heart failure before pacemaker implantation. American Journal of Cardiology 1238, 92: 1238-1240.

36. Bax J, Molhoek SG, van Erven L, Voogd PJ, Somer S, Boersma E, Steendijk P, Schalij MJ, Van der Wall EE: Usefulness of myocardial tissue Doppler echocardiography to evaluate left ventricular dyssynchrony before and after biventricular pacing in patients with idiopathic dilated cardiomyopathy. Am J Cardiol 2003, 91 :94-97.

37. Yu CM, Chau E, Sanderson JE, Fan K, Tang MO, Fung WH, Lin H, Kong SL, Lam YM, Hill MR, Lau CP: Tissue Doppler echocardiographic evidence of reverse remodeling and improved synchronicity by simultaneously delaying regional contraction after biventricular pacing therapy in heart failure. Circulation 2002, 105:438-445.

38. Alonso C, Leclercq C, Victor F, Mansour H, de Place C, Pavin D, Carre F, Mabo P, Daubert JC: Electrocardiographic predictive factors of long-term clinical improvement with multisite biventricular pacing in advanced heart failure. Am J Cardiol 1999 , 84:|4|7-|42I.

39. Molhoek SG, L VANE, Bootsma M, Steendijk P, Van Der Wall EE, Schalij MJ: QRS duration and shortening to predict clinical response to cardiac resynchronization therapy in patients with end-stage heart failure. Pacing Clin Electrophysiol 2004, 27:308-3।3

40. Bax IJ, Ansalone G, Breithardt OA, Derumeaux G, Leclercq C, Schalij MJ, Sogaard P, St John Sutton M, Nihoyannopoulos P: Echocardiographic evaluation of cardiac resynchronization therapy: ready for routine clinical use? A critical appraisal. J Am Coll Cardiol 2004, 44: I-9.

4I. Lecoq G, Leclercq C, Leray E, Crocq C, Alonso C, de Place C, Mabo $P$, Daubert C: Clinical and electrocardiographic predictors of a positive response to cardiac resynchronization therapy in advanced heart failure. Eur Heart J 2005, 26: 1094-I I00.

42. Chung ES, Leon AR, Tavazzi L, Sun JP, Nihoyannopoulos P, Merlino J, Abraham WT, Ghio S, Leclercq C, Bax JJ, Yu CM, Gorcsan J 3rd, St John Sutton M, De Sutter J, Murillo J: Results of the Predictors of Response to CRT (PROSPECT) trial. Circulation 2008, I I 7:2608-2616

43. Yu CM, Zhang Q, Fung JW, Chan HC, Chan YS, Yip GW, Kong SL, Lin $H$, Zhang $Y$, Sanderson JE: A novel tool to assess systolic asynchrony and identify responders of cardiac resynchronization therapy by tissue synchronization imaging. J Am Coll Cardiol 2005, 45:677-684.

44. Pitzalis MV, lacoviello M, Romito R, Guida P, De Tommasi E, Luzzi G, Anaclerio M, Forleo C, Rizzon P: Ventricular asynchrony pre- dicts a better outcome in patients with chronic heart failure receiving cardiac resynchronization therapy. J Am Coll Cardiol 2005, 45:65-69.

45. Yu CM, Lin H, Zhang Q, Sanderson JE: High prevalence of left ventricular systolic and diastolic asynchrony in patients with congestive heart failure and normal QRS duration. Heart 2003, 89:54-60.

46. Ghio S, Constantin C, Klersy C, Serio A, Fontana A, Campana C, Tavazzi L: Interventricular and intraventricular dyssynchrony are common in heart failure patients, regardless of QRS duration. Eur Heart J 2004, 25:57I-578.
Publish with BioMed Central and every scientist can read your work free of charge

"BioMed Central will be the most significant development for disseminating the results of biomedical research in our lifetime. "

Sir Paul Nurse, Cancer Research UK

Your research papers will be:

- available free of charge to the entire biomedical community

- peer reviewed and published immediately upon acceptance

- cited in PubMed and archived on PubMed Central

- yours - you keep the copyright 